\title{
MÁS ROMANCES DE LUISIANA
}

En 1978, publiqué en $N R F H$ un artículo sobre los romances tradicionales que aún se cantan en el diminuto islote lingüístico español de la "parroquia" de San Bernardo en el estado de Luisiana (Estados Unidos) ${ }^{1}$. Ulteriormente, gracias a una generosa subvención del Jean Lafitte National Historical Park (U.S. National Park Service) de Nueva Orleans, he podido ampliar notablemente mis encuestas, al emprender una extensa cam paña para salvar del olvido todo lo que aún sobrevive de literatura oral española en aquellas comunidades, junto con una amplia recolección de materiales lingüísticos. Desde el 13 de diciembre de 1980 hasta el 7 de enero de 1981, pude dedicarme a los trabajos de campo en San Bernardo. Después, he podido hacer otras tres visitas más breves a Luisiana: del 25 al 27 de febrero 1981, del 15 al 19 de marzo 1981 y del 14 al 28 de marzo 1982. Estas expediciones han resultado en una recolección amplísima (de un total de 58 horas de materiales grabados) y, según espero, representativa de todos los géneros folkliterarios que sobreviven entre los "isleños" de San Bernardo², amén de importantes informes sobre otros dos grupos españoles lingüísticamente diversos en los alrededores de Donaldsonville (Ascension, Assumption e Iberville Parishes) y de Natchitoches (Natchitoches y Sabine Parishes $)^{3}$. Estas dos últimas áreas dialectales —-muy reducidas las dos-

' S.G. Armistead, "Romances tradicionales entre los hispanohablantes del estado de Luisiana", NRFH, 27 (1978), 39-56.

2 Véanse mis reportajes: "Spanish language and folklore in Louisiana", LCo, 9 (1981), 187-189, e "Hispanic folk literature among the Isleños", Perspectives on ethnicity in New Orleans, ed. John Cooke y Mackie J.-V. Blanton, Nueva Orleans, 1981, pp. 21-31. Me complace agradecer al Sr. James L. Isenogle, Director del Jean Lafitte National Historical Park. su generoso apoyo a mis encuestas. Conste también mi profundo agradecimiento a todos mis informantes, cuya generosa hospitalidad y paciencia han hecho posibles mis investigaciones. En particular, tengo que destacar la ayuda de mis amigos, Frank Fernández e Irvan Pérez, quienes han alentado mis estudios a través de los años. Al Sr. Pérez, excelente cantor de décimas y conocedor como nadie de las tradiciones de su pueblo, debemos también el descubrimiento de la única versión de Delgadina $(9 A)$ que se conoce de San Bernardo.

${ }^{3}$ Para los otros dos dialectos, el español bruli de Donaldsonville y el español adaeseño de Natchitoches, véase, por ahora, lo que digo en mi artículo, "Adivinanzas españolas de Luisiana" (homenaje a Alvaro Galmés de Fuentes, en prensa). 
carecen hoy día prácticamente de toda manifestación folkliteraria, estando las dos hablas a punto de extinguirse. Por otra parte, junto con un español dialectal mucho más vigoroso ${ }^{4}$, subsisten entre los isleños restos - por lo menos- de una gran variedad de géneros de literatura oral. En mis encuestas, he podido coleccionar ejemplos de las formas siguientes: romances, décimas (de inspiración local), corridos, lírica tradicional, una canción acumulativa, rimas infantiles, adivinanzas, refranes, cuentos tradicionales y memorates (recuerdos personales narrados en forma tradicional) ${ }^{5}$. Las encuestas han resultado en un aumento, modesto, pero, según creo, significativo, de los testimonios romancísticos aducidos en mi artículo de 1978.

A los 20 textos y fragmentos allí publicados, he podido sumar otros 12, añadiendo a los siete temas narrativos descubiertos en 1975-1976 otros cinco - muy conocidos, por cierto, la mayoría de ellos - pero desconocidos hasta la fecha para el islote de San Bernardo. Contamos ahora con otros tres testimonios cada uno de $L a$ vuelta del marido (1DEF) y de Bernal Francés $(2 F G H)$ y otro parcialmente nuevo del Rondador rechazado ( $7 \mathrm{~B}$ bis). Al repertorio isleño, ahora podemos agregar la primera documentación de Delgadina $(9 A)$, de La fe del ciego (10AB), de La Virgen camino del Calvario (á-o) -sólo un exiguo fragmento de dos versos (10A.8-9)- de un romance vulgar, para mí desconocido, El galán que vuelve de las Indias $(\hat{a}-a)(11 A)$ y del conocidísimo romance de La hija de Juan Simón $(12 A)$. He aquí los textos:

\section{D. LA VUELTA DEL MARIDO (é)}

Versión de DELACROIX (St. Bernard Parish). Cantada dos veces por Irvan Pérez, de 56 años. Recogida el 17 y el 27 de diciembre de 1980, en Poydras (St. Bernard Parish).

-Yo soy la resién casada, de mí naiden gosará.

2 Mi marío a la guerra y a tomá su libertá.

Mi marío'ŝ alto y rubio y un viŝtí'o le corté.

Debo el conocimiento del adaeseño, hasta ahora totalmente ignorado por el hispanismo, a la gentileza de mi amigo, el profesor H. F. Gregory, de Northwestern State University (Natchitoches), quien conoce a fondo aquellas comunidades y lleva años hablando y estudiando su dialecto. Sobre el dialecto bruli, consúltese $\mathbf{R}_{\mathrm{AY}}$ MOND R. MACCuRdy, "A Spanish word-list of the Brulis dwellers of Louisiana", $H$, 42 (1959), 547-554.

${ }^{4}$ Sobre el dialecto, es de importancia crucial la monografía de R. R. M ACCuRdY, The Spanish dialect of St. Bernard Parish, Louisiana, Albuquerque, 1950.

${ }^{5}$ Hasta hace poco, los memorates no han sido reconocidos siquiera como un género independiente y auténtico de la literatura oral. Véase LiNDA DÉgh y A. V zONYI, "The memorate and the proto-memorate", $J A F, 87$ (1974), 225-239. 
4 Y en las mangaŝ 'e las espalda, yeva un letrero transę́. Mi marí'o eŝtá'n su guerra, con su vistí'o fransę́.

6. Yo me miro en el eŝpejo: «Qué guapa viuda no serél» -Señora, si usté quiere, nọ casaremǫ lọ dọ,

8 si's el guŝto mío y tuyo y la voluntar de Dio. - Hay seis año lo'spera'o y sei má lo'speraré,

10 si a lọ dose año él no viene, contigo me casaré. Yo tengo un vistí'o negro, jay! trę sastrę lo cortó.

12 - Mujer, uŝtéŝ́tá en luto, sin haberme muerto yo.

\section{IE. LA VUELTA DEL MARIDO (é)}

Versión de DELACROIX (St. Bernard Parish). Cantada dos veces por Joseph (Chelito) Campo, de 84 años. Recogida el 19 y el 21 de diciembre de 1980 .

- Yo soy la resién casada, de mí naide goserá.

2 Mi marí'o está en la guerra por servir su libertá.

-Señora, si usté quisiera, déme una seña de su marido:

4 - Mi marío es alto y rubio; nada tiene de corté. En el puño de su espada, yeva un letrero fransę́.

6 Hay seis año que lo eŝpero, seis más que lo eŝperaré. Si a lọ dose años no viene, con uŝté me casaré.

Comentario del informante: "Pero, lo otro se me olvida".

Variantes de la recitación del 21 de diciembre: $3 b$ me diera una seña de su marido. $/ / 6 b$ y seis más.

\section{IF. LA VUELTA DEL MARIDO (é)}

Fragmento de DELACROIX (St. Bernard Parish). Dicho por Leona (Nisha) Pérez García, de 77 años. Recogido el 27 de febrero de 1981, en Violette (St. Bernard Parish).

-Yo soy la resién casada,

2 Mi marido m'ha'baldonado Hay seis años que lo eŝpero,

que de mí naiden gosará.

4 Si en eŝtoŝ dose años no viene, con usté me casaré.

\section{F. BERNAL FRANCÉS $(i)$}

Versión de DELACROIX (St. Bernard Parish). Cantada por María Martínez, de unos 70 años. Recogida el 29 de diciembre de 1980, en Chalmette (St. Bernard Parish).

Y en este plan de barranco, sin saber cómo ni cuándo, 2 y ahí fu'ande s'alcontró y Elena con Juan Fernando. 
$-¿$ Qué hase usted, don Fernando?

4 ¿Tiene usted amores en Fransia -No tengo amores en Fransia,
8 Mira que soy tu marido, - Perdona, marido mío,

8 No lo hagas por mí, -De mí no tienes perdón,

10 Tú sola te deŝgrasiates; Toma, criada, este niño

12 Si te preguntan por Lena, Toma, criada, este niño

14 Si te preguntan por Lena, Toma, criada, este niño
¿Qué viene haser por aquí? o otra quiera más que a mí? ni otra quiero más que a ti. que me alcuentro junto a ti. perdona, sin desventura! hạlo por mis criatura. pide a Dios tu selitoria. y yévaselo a su madre. le dises que tú no sabes. y yévaselo a su padre. le dises que tú no sabes. y yévaselo a Mercéę. le dises que la maté.

\section{G. BERNAL FRANCÉS (í)}

Versión de DELACROIX (St. Bernard Parish). Cantada dos veces por Irvan Pérez, de 56 años, el 17 y el 27 de diciembre de 1980, en Poydras (St. Bernard Parish).

Con este plan de barranco, sin saber cómo ni cuándo,

2 y asina se alcontró Velina con don Fernando.

Y a mí me sacó el machete y el rifle de diesiseis.

4 Sinco balasos le pegué a don Fernando'l fransés.

A luego ya y se va y a luego no vuelveré

6 y a ponerse el visti'o de don Fernando'l fransés.

-Abréme la puerta, Velenia, abrémela con confiansa.

8 Mirá que soy tu querío, cabé viní de Fransia.Y apeną me abrió la puerta, yo le lumbré el candil.

10 Sobre una cama de flores, le quité el primer botín. -Ay, perdona, marío mío, perdón, por mi soletoria.

12 Tú no lo jagas por mí, haslo por mi criatura. - De mí tú no tienê̂s perdón, de mí tú no cantas vitoria.

14 Que tú meŝma te diŝsgrasiateŝ, pídele a tu soletoria. Cogé tuŝ niñoś, criadoŝ, yeváselo a tu marde.

16 Si te pregunta p'Ilenia, dile que tú no sabes. Cogé tuŝ niñoŝ, criadôs, yevál'a Dueña Isabel.

18 Si te pregunta p'llenia, tú dile que la maté.

Variantes de la recitación del 27 de diciembre: 8 a tu marío, $/ / 14 b$ díselo a tu s.; pídela su toletoria. // 16a, 18a p': entiéndase 'por'.

\section{H. BERNAL FRANCÉS $(i)$}

Fragmento de DELACROIX (St. Bernard Parish). Dicho por Leona (Nisha) Pérez García, de 77 años. Recogido el 27 de febrero de 1981, en Violette (St. Bernard Parish). 
En este plan de barranco, sin saber cuándo ni cuándo

2 y ayá fue onde s'alcontró Velina con don Fernando.

7B(bis). EL RONDADOR RECHAZADO (polias.)

Versión de DELACROIX (St. Bernard Parish). Cantada por José (Chelito) Campo, de 84 años. Recogida el 19 de diciembre de 1980.

Y un sábado por la tarde, toda tu caye pasedo,

2 por hablar con tus amigos, ya que contigo no puedo. El otro día domingo, fui d'en casa delantero,

4 por ver si te vide venir y con ese lindo cuerpo. Cuando te vide venir, me tapé con el sombrero,

6 porque no diga tu padre que por tus amores muero. Entrates en la iglesia; de rodiyas ves al Sacramento,

8 a rogarle y a pedirle: Dio nos libre del infierno. Cuando a ti te'ŝtén echando las alas en el pañuelo, 10 a mí me eŝtarán echando mi cuerpo en el simenterio. Cuando a ti te'ŝtén sacando a bailar los buenos mosos, 12 a mí me eŝtarán sacando los gusanitos los ojo.

\section{A. DELGADINA $(a ́-a)$}

Versión de REGGIO (St. Bernard Parish). Cantada tres veces por Josephine (Fin) Acosta, de unos 60 años. Recogida por Irvan Pérez, hacia el 5 de junio de 1981 y, otras dos veces, por S. G. Armistead, el 24 de marzo de 1982.

Había un rey que tenía tres hijitas

2 y la más pequeñita Delgadina se llamaba.

Y cuando su madre dí'a misa, su padre la enamoraba.

$4 \mathrm{Y}$ como eya no quería, en un cuarto la enserraba; en un cuarto tan d'escuro, de onde las ranas cantaban.

6 A los tres días de ensierro, Delgadina'n su ventana. Y alcansó a ver su hermana, jugando un juego de amas:

8 - Hermana, por ser mi hermana, ¿me darás un trago de agua? Que de esta hambre y d'esta sed, y'a Dios pienso dal del alma.

10 - Pasa, pasa, perra malgada, quítate d'esa ventana, que si mi padre te ve y puñaladas te daba.-

12 Delgadina se quitaba, muy triste y desconsolada. Y con las lágrimas de los ojos, todo'l cuarto lo bañaba.

14 A los seis días de ensierro, Delgadina en su ventana. $\mathrm{Y}$ alcansó a ver s'otra hermana, jugando un juego de amas:

16 - Hermana, por ser mi hermana, ¿me darás un trago de agua? Que de esta hambre y d'esta sed, y'a Dios pienso dal del alma.

18 -Pasa, pasa; perra malgada, quítate d'esa ventana, que si mi padre te ve y puñaladas te daba.- 
20 Delgadina se quitaba, muy triste y desconsolada.

Y con las lágrimas de los ojos, todo'l cuarto lo bañaba.

$22 \mathrm{Y}$ a los nueve días de ensierro, Delgadina en su ventana.

Y alcansó a ver su padre, namorando otra dama:

24 -Padre, por ser mi padre, ¿me darás un trago de agua?

Que de esta hambre y d'esta sed, y'a Dios pienso dal del alma.

26 - Vaigan, cabayeros, denle agua a Delgadina!

- No me la den en tasas de oro, ni en vasos de plata;

28 denme una copa de cristal, para que me refresque el alma.-

Y en la gloria las campanas repicando y los angelitos cantando,

30 porque, al montar las escaleras, Delgadina muerta estaba.

\section{A. LA FE DEL CIEGO $(\dot{e})+$ LA VIRGEN CAMINO DEL CALVARIO (á-o)}

Versión de DELACROIX (St. Bernard Parish). Recitada por Julia Melerine Schiel, de 80 años. Recogida el 29 de diciembre de 1980, en Chalmette (St. Bernard Parish).

Âhi arriba en aquel alto venden ricos narajeros.

2 Siego es el que lo vende; siego es el que no ve.

- Siego, déme una naraja para mi niño comer.

4 - Entra adrento, la señora, y coja lạ que quisiere.-

Una cogió para mi niño comer y sientạ volvieron a naser.

6 Camina la Virgen pura y camina para Belén, con su niño entre los brasos, qu'ę el Jesús de Nasarén.

8 Cuando eya día llegando, ya lo estaban crusificando. Cuando eya yegó, ya le habían remachado los clavos.

10B. LA FE DEL CIEGO $(\dot{e})$

Fragmento en prosa de DELACROIX (St. Bernard Parish). Dicho por Martín Alfonso, de 65 años. Recogido el 28 de marzo de 1976.

Dise: «¿uánto...?» Había un vergel yeno de narajas. Y el niño 'ise: «Quisiera tener una.» Dise: «Deŝscoja usted la que usted quiera.» $Y$ eya le dijo: «Para mi niño comer.» Y eya dise... Eya le cogió una; dise: «Cuando yo cogí ésta, sien más ... van a naser...»

Comentario: "Mi marde la sabia". (La se refiere a la décima; o sea "la canción'.)

\section{1 $A$. EL GALÂN QUE VUELVE DE LAS INDIAS $(a ́ a)$}

Versión de DELACROIX (St. Bernard Parish). Recitada (vv. 1-2) por Lilly López Rayburn, de 78 años, y cantada (vv. 3-14) por Julia Melerine Schiel, de 80 años. Recogida el 29 de diciembre de 1980, en Chalmette (St. Bernard Parish). 
Ahí vinía mi papá arriba de su caballo,

2 a darme las nuevas que ya me habían matado a mi esposo.[...] Vístanme mi casa 'e luto, de luto tamién mi cama.

4 Pónganme camisas negras y negras también mis sayas. Que se me van para las Indias lo dos ojo de mi cara.

6 Y el galán enternesido juró a la crus de su espada, que al cumplir el año y medio y en cumplir en su palabra.

$8 \mathrm{Y}$ antes de cumplir el año y medio, ya la dama era casada, con un rico mercadero ayí mismito de España.

$10 \mathrm{Y}$ al cumplir el año y medio, y el galán en tierra estaba. $Y$ a la primera vesita, sentadita en su ventana,

12 con un niñito en los braso que el mismo sol lo envidiaba. -Quédese con Dios, señora, yo de usté no quiero nada.

14 - Váyase con Dios, señor, que yo he sido la engañada.

\section{A. LA HIJA DE JUAN SIMÓN (ó)}

Versión de DELACROIX (St. Bernard Parish). Cantada por Nicolás (Casito) Pérez, de unos 80 años, y por Malvina (Chica) Pérez, de unos 65 años. Recogida el 23 de marzo de 1982.

No meresites, tirana, tú a mí,

2 que soy tu amante rendi'o.

Tú m'hạ d'olvidar mañana

4 por cuento que te han ponío.

Un domingo por la tarde, enterraron a la hija de Juan Simón.

6 Juan Simón era en el pueblo el único enterrador.

El meśmo a su propia hija la sepultura arregló,

8 con una mano en la pala, la otra en el asador, [.......... cantando un orasión.

10 La gente le preguntaban: - ¿De ónde vienę, Juan Simón? -Yo soy enterrador; vengo de enterrar mi hija, mi dulse amor.

Variantes:1 Tú me dešpresias, tirana, a mi.//7b la s. le dio.// $8 b$ Entiéndase: 'azadón'.

Las tres versiones de La vuelta del marido (1DEF) no proporcionan, en general, grandes novedades frente a las tres $(1 A B C)$ que publiqué en 1978. A parte de pequeñas variantes verbales, caracterís* ticas y siempre interesantes en todo tex to oral, lo único notable es el motivo - nuevo para esta sub-tradición - de la viuda guapa que se mira en el espejo ( $1 D .6)$, muy común por cierto en otras regiones ${ }^{6}$, y

${ }^{6}$ Compárense, por ejemplo: "y me vide en el espejo. / —Qué linda viuda he quedado!" (A. M. Espinosa, Romancero de Nuevo Méjico, Madrid, 1953, núms. 12, 14; A. L. CAMPA, Spanish folk-poetry in New Mexico, Albuquerque, 1946, p. 43); "y me miro en un espejo: / -iQué bonita está la viuda!" (G. BEurLer, Estudios sobre el romancero español en Colombia, Bogotá, 1977, núms. 212-214); “a mirarme en un espejo, / a ver qué hermosa quedé" (Beutler, núms. 217-218). 
el marido, implícitamente un tanto presumido, con su "visti'o fransé"' (v. 5), que no conozco de otros textos. Nótese como nuestro IF.2a trae la variante abandonado,presente también en el texto de MacCurdy (el primer romance recogido en San Bernardo) $)^{7}$ y en algunos de Nuevo México e incluso de Colombia ${ }^{8}$. Corté $[s](1 E .4 b)$ carece de significado para los cantores y se asocia, por etimología popular, con corto o bajo; por lo tanto, el marido, alto de estatura, nada tiene de bajito. Los versos con que terminan nuestros textos $1 A$ y $l E$, así como el de MacCurdy, vienen de una copla difundidísima. MacCurdy la encuentra en Nuevo México, pero se conoce también en México, España y la Argentina ${ }^{9}$. El desenlace de la versión $1 B$ incorpora el mismo tópico y es indudablemente tradicional, pero no conozco, por ahora, congéneres en otros ámbitos geográficos. Todos los textos de La vuelta del marido de Luisiana recogidos hasta la fecha están "incompletos"; muchos se complementan unos a otros. Ante el testimonio adicional de las versiones de Nuevo México (estrechamente emparentadas con las nuestras), para lo que se refiere al orden de los versos, creo que estamos en condiciones de ofrecer un texto facticio que encierre todos los elementos dispersos en las siete versiones actualmente a nuestro alcance $(M=$ la versión de MacCurdy; amante, en v. 14b, significa 'diamante'):

*-Yo soy la resién casada;

2 Me albandonó mi marí'o - Señora, déme usté nuevas

4 - Mi marío es alto y rubio, En el puño de su espada, de mí naiden gosará. (MABCDEF) y a tomá su libertá. $(M A B D E F)$

pa poderlo conoser. $(M B / M)$ nada tiene de cortés. ( $M A B C E)$ yeva un letrero fransés. $(M A C D E)$

6 -A las señas qu'usté m'ha da'o, su marío muerto es. $(M)$ En la bataya de Cádis, lo mató un traidor fransés. $(M / M C)$

8 Señora, si usté quisiera, nos casábanos los dos, $(A B C D)$ con el gusto d'usté y el mido y la voluntar de Dios. $(A B C D)$

10 - Mi marío 'stá'n su guerra, con su visti'o fransés. $(D)$ Yo me miro en el espejo: «Qué guapa viuda no seré!» $(D)$

12 Hay seis años que lo espero y seis más lo esperaré. ( $M A B C D E F$ ) $\mathrm{Si}$ a los dose no vuelve, con usté me casaré. (MABCDEF)

14 - Le merqué un visti'o nuevo y un amante chocolata'o. $(B)$ Mi mujer carga luto y a mí naiden me ha mata'o. $(B)$

16 Usté tiene un vistí'o negro; tres sastres se lo cortó. (MAE) Mujer, ustéstá en luto sin haberme muerto yo.* $(M A E)$

${ }^{7}$ R. R. MACCuRdy, "Un romance tradicional recogido en Luisiana: Las señas del marido", RHM, 13 (1947), 164-166, o bien mi artículo en NRFH, 27 (1978), p. 42.

${ }^{8}$ Espinosa, núms. 14-17; Beutler, núms. 210, 216, 217, 219-222.

${ }^{9}$ Véase MACCuRdy, "Un romance", p. 165, n. 7; Julio VIGGIANo Esafn, Cancionero popular de Córdoba, 2 tomos, Córdoba (Argentina), 1969-1971, II, 9 (núm. $2184)$; más ejemplos: C. H. MAGis, La lírica popular contemporánea, México, 1969, pp. 35-36. 
Los textos de Bernal Francés, igual que los de La vuelta del marido, reflejan un tipo textual "vulgata" de vasta difusión en Hispanoamérica. Las tres versiones nuevas $(2 F G H)$ concuerdan de cerca con los cinco recogidos en 1975-1976, pero los dos nuevos suplen un desenlace, no documentado hasta ahora en Luisiana, en que el marido furioso se dirige a la criada para que se encargue de los niños (2F.11-16; 2G.15-18). En esta enumeración "incremental", que acaba dramáticamente con el anuncio de la muerte de la desgraciada Elena, no está claro en $2 F$ quién se ha de encargar de los niños, pues huelga decir que no va a ser "su madre" — muerta por adúltera - ni tampoco "su padre", que es quien ordena que la criada se los lleve; $2 G$, donde se trata, al parecer, de la madre de los "criados" y de "Dueña Isabel", tiene algo más de sentido. En textos de Nuevo México, donde también se dan versos parecidos, más lógicamente los niños se han de dar a "su agüela", a "mi suegra" o a "mis padres" 10. La acumulación incremental de parientes, como en $2 G$, es un recurso que tiene su contraparte en otros muchos romances (Delgadina, aquí supra y otros) ${ }^{11}$. Es divertido como la voz misericordia, vacía, al parecer, de contenido semántico en el dialecto y sujeta a diversas deformaciones, genera fantásticas creaciones a base de asociaciones folk-etimológicas con los adjetivos posesivos: Si existe mi soletoria, cuando se habla en primera persona, pues lógicamente, ¿cómo no ha de existir también tu soletoria o tu selitoria, cuando la frase se dirige a otro individuo en segunda singular. El Viyano, Velina, Velino, del v. $2 b$ refleja, sin duda, el Benigno que figura en textos de otras regiones. Como en el caso de La vuelta del marido, todos los textos isleños son defectuosos y se complementan mutuamente. He aquí un ensayo de reconstrucción facticia a base de todos los diversos elementos presentes en nuestras ocho versiones y fragmentos:

*En este plan de barranco, sin saber cómo ni cuándo, $(A B C D F G H)$

2 ayí fu'onde se alcontró Velino con don Fernando. ( $A B C D F G H)$ Metió mano a su machete y al rifle de a diesiseis. ( $A C D G$ )

4 Sinco balasos le pegó a don Fernando el fransés. ( $A C D G$ ) Ahí luego él se día y volvió otra ves, $(A D G)$

6 a ponerse y el vistío de don Fernando el fransés. $(A D G)$ -Abréme la puerta, llena, abréme sin desconfiansa. ( $A C D E G)$

8 Mirá que soy don Femando, que acabé yegá de Fransia.-( $A C D E G)$ Apenas le abrió la puerta, él vino y apagó el candil. ( $A C D E G)$

10 Véanse Espinosa, núms. 58, 60, 61; Campa, p. 39; también A. Paredes, $A$ Texas-Mexican 'Cancionero', Urbana, Illinois, 1976, pp. 16-17; Beutier, núms. 141-142, 144; E. M Ejá S Anchez, Romances y corridos nicaragüenses, México, 1946, pp. $49-57$.

${ }^{11}$ Cf., p. ej., S. G. Armistead y J. H. Silverman, En torno al romancero sefardí: Hispanismo y balcanismo de la tradición judeo-española, Madrid, 1982, p. 155. 
10 Se cogieron por las manos y se fueron al jardín. $(A C D)$ Ayí l'ha vistío de blanco, que paresía un serafín. ( $A C D)$

$12 \mathrm{Y}$ en una cama de flores, le quitó el primer botín. (CDEG) - ¿Qué dise usted, don Fernando, qué viene haser por aquí? $(B F)$

14 ¿Tiene usted amores en Fransia o asotra quieres más que a mí?(BF) - No tengo amores en Fransia, ni asótra quiero más que a ti. $(B F)$

16 Vengo que veas tu marío, que s'alcuentra al la'o de ti. $(B F)$ - Perdona, esposo mío, perdona mi desventura! $(A B F G)$.

18 No lo jagas por mí, haslo por mis criaturas. $(A B F G)$ -De mí no tienes perdón, de mí no alcansas vitoria. $(A B F G)$

20 Tú sola te desgrasiates, pide a Dios miselicoria. $(A B F G)$ Toma, criada, estos niños y yévaselos a tu madre. $(F G)$

22 Si te pregunta por 'Lena, le dises que tú no sabes. $(F G)$ Toma, criada, estos niños y yévaselos a $[\mathrm{tu}]$ padre. $(F)$

24 Si te pregunta por 'Lena, le dises que tú no sabes. $(F)$ Toma, criada, estos niños, yevál'a Dueña Isabel. $(F G)$ 26 Si te pregunta por 'Lena, le dises que la maté.* $(F G)$

Nuestro texto $7 B($ bis $)$ del Rondador rechazado es variante de un texto fragmentario cantado ya por Chelito Campo en 1975. Aparte de la lectio facilior "lindo" (por "raigado") en el v. $4 b$, es interesante esta recitación por suplir otros seis versos (vv. 7-12) a lo recogido años antes. Todos estos versos recuerdan elementos dispersos en la amplia versión dicha por Paulina Díaz (7A.8a, 10, 11, 26-29). Parece posible que el romance puede haherse compuesto originalmente de dos poemas au tónomos: lo del rondador, en asonancia $e ́-o(7 A .1-17)$, y las amonestaciones y despedida amarga del novio airado, con coplas asonantadas ( $7 A \cdot 18-29)$. Claro está que esta yuxtaposición se produjo ya en la tradición peninsular. Las dos versiones de Luisiana siguen pareciéndome muy afines a las peninsulares. Lo que no es cierto, según yo suponía, es que el poema -o bien lo de las amones-

- taciones, por lo menos- sea desconocido en América. Téngase en cuenta el amplio estudio de Vicente $T$. Mendoza a base de textos españoles y americanos ${ }^{12}$.

Nuestra versión única de Delgadina $(9 A)$, -el romance más amplio y más cabal de todos los recogidos hasta la fecha en la comarca- es interesante, no sólo por su conservación relativamente buena y por la hermosa tonada con que se canta, sino por atestiguar un elemento antillano hasta ahora ignorado en el repertorio isleño. El texto de Luisiana concuerda bastante más con los de Santo Domingo e incluso con algunos cubanos y puertorriqueños que con

12 "La canción del novio desairado", AIIE, 22 (1954), 55-88. Una versión sefardí de Tetuán sólo corresponde al principio con nuestros textos. Véase $\mathbf{S}$. G. A R mistead et al., El romancero judeo-español en el Archivo Menéndez Pidal: Catálogo-Índice de romances y canciones, 3 tomos, Madrid, 1978, núm. SI2. 
los de Nuevo México, México y Centro América ${ }^{13}$. El “juego de amas" es, claro está, de "damas".

El texto del $F$ e del ciego $(10 \mathrm{~A})$, también único hasta ahora para estas comunidades, trastrueca dos segmentos del romance apócrifo -conocidísimo en toda España e Hispanoamérica ${ }^{14}$. Los vv. 6 y 7 corresponden al comienzo; mientras $1-5$ concentran el interés en la milagrosa generación de nuevas naranjas, olvidándose por completo de la restauración taumatúrgica de la vista del ciego. El exiguo fragmento en prosa $(10 B)$, que había dejado sin transcribir de las cintas de 1976, corresponde efectivamente a los vv. $4 b, 3 b$ y 5 del romance, conservando incluso dos asonancias: comer y nacer. La alusión al vergel nos demuestra que la madre de Martín Alfonso sabía una versión más cabal que nuestro texto $10 A^{15}$.

Los dos versos finales del $10 \mathrm{~A}$ pertenecen al romance tradicional bíblico, La Virgen camino del Calvario (á-o). De América, no tengo a mano sino un solo texto chileno de Vicuña Cifuentes, pero esto no significa que no haya pasado por alto otros. Hay abundantes testimonios de España y Canarias ${ }^{16}$. Para nuestros versos, compárense

13 Compárense, por ejemplo, los textos que recogen E. Garrido, Versiones dominicanas de romances españoles, Santo Domingo, 1946, pp. 25-27; F. DE Nolasco, La poesía folklórica de Santo Domingo, Santiago, 1946, pp. 324-327; P. Henrfouez URENA, "Romances en América", Cuba Contemporánea, 3 (1913), 347-366; C. Poncet y de Cárdenas, El romance en Cuba, La Habana, 1972, pp. 120-126; J. M. Chacón y Calvo, "Romances tradicionales en Cuba", $R F L C$, 18 (1914), 45-121: pp. 81-83; M. J. CaninoS ALGado, El cantarfolklórico de Puerto Rico, San Juan, 1974, pp. 377-383. Uno de estos textos puertorriqueños trae, incluso, la variante, bastante distintiva, de las ranas (nuestro v. $5 b$; Canino, p. 382). Contrástese nuestro texto con los de Espinosa, núms. 26-36; Campa, pp. 32-33; V. T. MENDozA, El romance español y el corrido mexicano, México, 1939, pp. 345-354; C. Navarrete, "El romance tradicional y el corrido en Guatemala", USC, 59 (1963), 181-254: pp. 188-190; Mejía Sánchez, pp. 60-66. No existe ningún estudio exhaustivo, muy de desear, por cierto, de Delgadina en toda la tradición hispánica. El número de versiones es, huelga decir, enorme. Para Hispanoamérica, véase, por ahora, la extensa bibliografía de Beutler, pp. 487-488 (a la que puedo sumar ejemplos de Tejas, Venezuela, y Uruguay) y para referencias panhispánicas, mi Catálogo-Índice, núm. P2, y S. G. Armistead y J. H. Silverman, Romances judeoespañoles de Tánger, Madrid, 1977, p. 144.

14 Véase, para Hispanoamérica, la bibliografía de Beutler, p. 484 (núm 2); se da también en Puerto Rico y Costa Rica. Para textos de otras tradiciones, véanse, por ejemplo, J. M. DE Cossfo y T. M AzA Solano, Romancero popularde la Montaña, 2 tomos, Santander, 1933-1934, núms. 426-434; B. Gil G ARCfA, "Romances tradicionales de la Rioja", separata de Berceo, 17-18 (Logroño, 1962), núm. 35; D. C.ATALAN et al., La flor de la marañuela: Romancero general de las Islas Canarias, 2 tomos, Madrid, 1969, 2, 236 (núm. 66); José LeITE dE V ASCONCELos, Romanceiro português, 2 tomos, Coimbra, 1958-1960, núms. 759-765; entre otros muchos que se podrían citar.

${ }_{15}$ Para versiones con la lectura vergel, véase, p. ej., Flor de la marañuela, núms. 520, 569, 570 .

16 Véanse J. Vicuña Cifuentes, Romances populares y vulgares, Santiago de Chile, 1912, núm. 86; Cossio-Maza, núms. 441-453; J. Marazuela Albornos, Cancio- 
éstos de una versión de la Montaña: "que por presto que lleguemos, / ya le habrán crucificado. // Ya le ponen las espinas, / ya le remachan los clavos" (Cossío-Maza, núm. 443).

El romance $11 A$, El galán que vuelve de las Indias, representa un tema ignorado, por lo menos según mis conocimientos del Romancero. Trátase obviamente de un romance vulgar de pliego de cordel. Nos lo dicen tanto el giro característicamente seudoerudito "que el mismo sol lo envidiaba", como el tópico del juramento en la cruz de la espada (por épico que parezca) ${ }^{17}$. Nótese que el texto es sensiblemente menos dialectal que los demás que hemos recogido, apuntando seguramente a un origen escrito relativamente reciente. Una exploración detenida de las publicaciones de cordel de los siglos XVIII y XIX, muy de desear, seguramente nos daría un texto cabal del poema ${ }^{18}$.

La hija de Juan Simón (12A) es, claro está, conocidísimo en toda España. Sin embargo, no tengo a mano ninguna versión publicada. He aquí la que yo mismo aprendí hace años: "Enterraron por la tarde / a la hija de Juan Simón. // Y era Simón en el pueblo / el único enterra'or. // El mismo a su propia hija / al cementerio llevó. // El mismo cavó la fosa, / murmurando una orasión. // Y cuando todos le preguntamos: / —De 'ónde vienes, Simón? // -Soy enterra'or y vengo / de enterrar mi corazón." Que haya pasado a América - y sin duda repetidas veces además - nos lo asegura el texto mexicano publicado por M. L. Wagner ${ }^{19}$. De alguno de los muchos inmigrantes andaluces residentes en Delacroix en las primeras décadas de este siglo lo aprendería, con toda seguridad, el Sr. Nicolás Pérez. Ha de ser tradicional el preludio lírico, temáticamente ajeno al romance (vv. 1-4). Nótese como la siguiente versión andaluza, recientemente comercializada, comienza con unos versos líricos diferentes, pero también con asonancia en $i$-o:

Cuando acabé mi condena,

2 me vide solo y perdí’o.

Ella se murió de pena

nero Segoviano, Segovia, 1964, pp. 377-378; GIL GARCiA, "Romances tradicionales de la Rioja”, núm. 41; Flor de la marañuela, II, 237 (núm. 77). Cf.también L. R. DE Jijena Sanchez, Poesía popular y tradicional americana, Buenos Aires, 1952, pp. 140 141 (versión de Nicaragua).

${ }^{17}$ Cf. Armistead-Silverman, Romances judeo-españoles de Tänger, p. 137, n. 3; The Judeo-Spanish ballad chapbooks of Y.A. Yoná, Berkeley-Los Angeles, 1971, pp. $187-188$, n. 3.

18 Buenos comienzos son el útil catálogo de F. Aguilar Piña, El romancero popular en el siglo xviii, Madrid, 1972, así como los abundantes pliegos sueltos descritos por Pilar Garcia de Diego, "Pliegos de cordel", RDTP, 27-29 (1971-1973). Pero, con todo, queda muchísimo por hacer.

19 "Algunas apuntaciones sobre el folklore mexicano", $J A F, 40(1927), 105-143$ : pp. 133-134. 
4 y dijo que la causa ha sí'o... Sé que murió siendo buena.

6 Enterraron por la tarde a la hija de Juan Simón. Era Simón en el pueblo el único enterra'or.

$8 \mathrm{El} \mathrm{mismo} \mathrm{su} \mathrm{propia} \mathrm{hija} \mathrm{al} \mathrm{cementerio} \mathrm{llegó.}$ Y el mismo cavó la fosa, musitando una oración.

10 Como en una mano llevaba la pala y en el hombrol'aza'ón, los amigos le preguntaban: _De dónde vienes, Juan Simón?-

$12 \mathrm{Y}$ todos le preguntaban: - ¿A dónde vienes, Juan Simón? -Soy enterra'or y vengo d'enterrar mi corazón ${ }^{20}$.

Estos doce textos romancísticos recogidos últimamente en San Bernardo, junto con el testimonio de los demás géneros tradicionales allí conocidos, nos obligan a modificar, hasta cierto punto, nuestro juicio sobre esta exigua sub-tradición del Romancero hispánico. Ante el obvio carácter hispanoamericano de las versiones de $L a$ vuelta del marido y Bernal Francés - muy influidos en su forma por el corrido ${ }^{21}$ y muy afines a las versiones corrientes en el suroeste de los Estados Unidos, en México y en Centro América- había insistido en que la tradición hodierna de San Bernardo representaba "esencialmente una modalidad hispanoamericana del Romancero pan-hispánico" (NRFH, 1978, p. 44). Ahora, con algo más de documentación a mi alcance, creo que convenía matizar ese juicio. Frente a textos de tradición esencialmente americana como La vuelta del marido y Bernal Francés y, por algunas de sus lecturas, también El pretendiente burlado (6), nos las tenemos, por otro lado, con una Delgadina $(9 \mathrm{~A})$, de clara derivación antillana, y también con otros romances de diversos tipos que han de proceder seguramente de España: un romance vulgar y tardío como el Rondador rechazado, otro como El galán que vuelve de las Indias, basado obviamente en algún pliego suelto, y La hija de Juan Simón, de conocidísimas resonancias andaluzas. En otra parte, he insistido recientemente en

20 "El Perro de Paterna", La hija de Juan Simón y otros éxitos, RCA Records (Madrid, 1977: Indalo 33143, YEL-811). Respecto a La hija de Juan Simón, no puedo por menos de reproducir la siguiente anécdota de la Guerra Civil Española: Al ser disuelta la junta defensiva de Madrid (primavera 1937), por Largo Caballero, reaccionando en contra del creciente poder comunista, un miembro republicano izquierdista, Carreño España, acusa a los comunistas, en la última reunión: "Sois el Juan Simón de la junta defensiva..." (re-traduzco el texto inglés de Ronald F Faser, Blood of Spain: An oral history of the Spanish Civil War, Nueva York, 1979, p. 298). Hasta cierto punto, los españoles del siglo xx han seguido, igual que los de los siglos de oro, proverbializando su romancero, al incorporarlo al habla de todos los días. Sobre algunos casos áureos, véase $\mathbf{R}$. Mentendez Pidal, Romancero hispánico, 2 tomos (Madrid, 1953), II, 184-189.

21 Sobre la influencia del corrido en la poesía tradicional isleña, véanse mis artículos, "Hispanic traditional poetry in Louisiana", El Romancero hoy: Nuevas fronteras, ed. A. Sánchez Romeralo et al., Madrid, 1979, pp. 147-158, y "Un corrido sobre la muerte de Madero cantado en Luisiana”, $A L M, 20$ (1982), 379-387. 
el carácter ecléctico de la literatura oral de San Bernardo como un fiel reflejo de la etnografía y la historia de esa minúscula comunidad hispana ${ }^{22}$. Una colonización original, proveniente de las Islas Canarias a finales del siglo XVIII (a partir de 1778), ha sido constantemente reforzada a través de los años, en lo que se refiere a su cultura hispánica, por la llegada de nuevos inmigrantes de diversas regiones de la Península Ibérica. Hoy día, los isleños tienen plena conciencia -y orgullo bien justificado - de sus raíces canarias. Pero al realizar mis encuestas, apenas encontraba una familia que no dijera que el padre o la madre, el abuelo o la abuela, eran de España - algunas veces propiamente de Canarias- pero, en otros muchos casos, de Galicia, de la Montaña, de Cataluña o Andalucía, o bien de Portugal, como lo demuestran las tradiciones de algunas familias, así como una serie de apellidos isleños: Acosta, Acevedo, Meneses. Estos inmigrantes nuevos de la Península, junto con la proximidad geográfica de Cuba, México y el suroeste, y de Centroamérica a través del Golfo, son factores que habían de influir decisivamente en el destino cultural de la comunidad. Han asegurado la pervivencia de la lengua y la cultura españolas en los pueblos de San Bernardo y han dado lugar a que sus tradiciones folkliterarias acaben siendo una confluencia rica, heterogénea y única de elementos provenientes de muy diversas comunidades del mundo hispánico.

SAMUel G. ARMiSTEAD

University of California, Davis.

${ }_{22}$ Véase mi reportaje en Perspectives on ethnicity (citado en la $\mathbf{n} .2$ supra). Sobre la etnografía de los isleños, téngase en cuenta la excelente monografía de mi amigo, Joseph V. Gullotte, Masters of the Marsh: An introduction to the ethnography of the Isleños of Lower St. Bernard Parish, Louisiana (New Orleans: University of New Orleans, 1982). Para más datos sobre la literatura oral de los isleños, véase ahora mi artículo, "Spanish riddles from St. Bernard Parish", Louisiana Folklore Miscellany, 5 (1983), 1-8. 